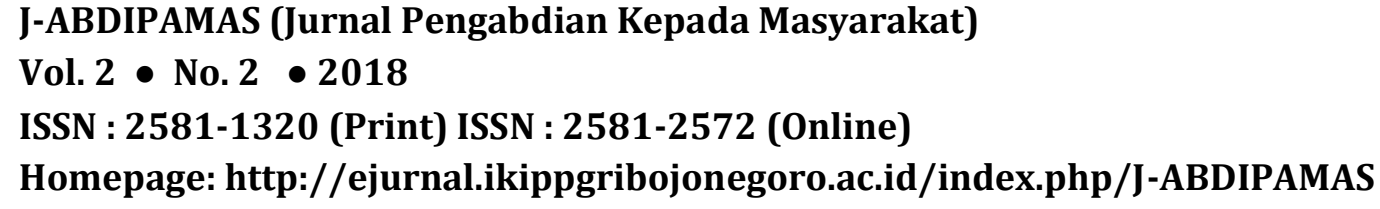

\title{
PELATIHAN PEMBUATAN MEDIA PEMBELAJARAN 3D DENGAN MEMANFAATKAN MEDIA POP UP DAN APLIKASI “MOMENTCAM KARTUN \& STIKER” BAGI GURU MTS. BAHRUL ULUM BULU BALEN
}

\author{
Cahyo Hasanudin ${ }^{1}$, Fathia Rosyida ${ }^{2}$, Siti Ermawati ${ }^{3}$, Taufiq Hidayat ${ }^{4}$ \\ 1IKIP PGRI Bojonegoro. Email: cha.sanu.88@gmail.com \\ 2IKIP PGRI Bojonegoro. Email: f.rosyida57@gmail.com \\ 3IKIP PGRI Bojonegoro. Email: siti ermawati@ikippgribojonegoro.ac.id \\ ${ }^{4}$ IKIP PGRI Bojonegoro. Email: taufiq hidayat@ikippgribojonegoro.ac.id
}

\begin{abstract}
The purpose of this service is so that 1) Teacher of Mts. Bahrul Ulum can operationalize the momentCam application, 2) Teacher of Mts. Bahrul Ulum can make 3D understanding media through pop ups. The method of implementation in this service is 1) Conducting pretest, 2) counseling and coaching, 3) holding postes, and organizing reflection. The service scheme starts from the pre-service, dedication and post-service steps. The results of dedication show the teachers in MTs. Bahrul Ulum can be a Momencam application and can make pop up media, this can be seen from the results of the posting In addition, teachers can create their own media and they will implement the results of this service program to students. The conclusions in this service are the teachers at Mts. Bahrul Ulum can create 3D learning media.
\end{abstract}

Keywords: 3D learning media, momentcam application media, pop up media, teacher.

\begin{abstract}
ABSTRAK
Tujuan pengadian ini adalah agar 1) Guru Mts. Bahrul Ulum dapat mengoprasionalkan aplikasi momentCam, 2) Guru Mts. Bahrul Ulum dapat membuat media pembelajaran 3D melalui pop up. Metode pelaksanaa pada pengabdian ini adalah 1) mengadakan pretes, 2) penyuluhan dan pembimbingan, 3) Mengadakan postes, dan mengadakan refleksi. Skema pengabdian dimulai dari langkah prapengabdian, pengabdian, dan pascapengabdian. Hasil pengabdian menunjukkan guru-guru di MTs. Bahrul Ulum bisa mengoperasikan aplikasi momentcam dan dapat membuat media pop up, hal ini dapat dilihat dari hasil postes. Selain itu guru dapat menciptakan media sendiri dan mereka berkomitmen untuk menerapkan hasil program pengabdikan ini kepada peserta didik. Simpulan dalam pengabdian ini adalah guru-guru di Mts. Bahrul Ulum dapat membuat media pembelajaran 3D.
\end{abstract}

Kata kunci: Media pembelajaran 3D, media aplikasi momentcam, media pop up, guru.

\section{PENDAHULUAN}

Pada zaman sekarang, banyak sekali orang dapat menemui pop up dalam berbagai bentuk dan di berbagai tempat. Namun, sebenarnya pop up sudah ada sejak beberapa ratus tahun yang lalu. Pop up merupakan gambar dua atau tiga dimensi yang sudah ada sejak 800 tahun lalu. Penikmat dan penyuka pop up bukan saja anak-anak namun pop up juga disukai oleh orang tua dan dewasa sudah sejak lama. Pada awalnya penggunaan pop up dimulai pada abad ke-13 oleh orang-orang Catalan mistik dan penyair Ramon Llull yang menggunakan potongan kertas yang dapat diputar untuk mengilustrasikan teorinya. Pada masa ini, buku dengan ilustrasi pop up mulai dikenal dan digunakan 
untuk pengajaran dan penyampaian ide dengan ilustrasi. Salah satu pop up atau yang bisa ditemukan hingga sekarang adalah milik Peter Apian yang berjudul "Astronomicum Caesareum" yang diterbitkan pada tahun 1540. Buku ini, berisi ilutrasi yang didesain untuk menghitung ilmu astronomi dan data astronomi. Pada abad ke 19 pop up mulai banyak dibuat untuk tujuan pembelajaran dan pengajaran moral (Puelo, 2011:10). Van Dyk dan Hewwit (2011:5) menyebutkan sejarah tentang pop up dimulai pada abad medival monastery atau sekitar abad pertengahan. Buku-buku yang berisi tentang pop up berisi tentang catatan, informasi dan juga hitungan data. Buku pop up digunakan untuk mengilustrasikan hitungan data dari posisi bintang, kalender gereja, tanda-tanda bintang dan sebagainya.

Semakin hari, pop up banyak digunakan dan dikenal oleh orang-orang baik sebagai ilustrasi dari sebuah cerita yang dipadupadankan dengan teks cerita atau sebagai objek tanpa teks seperti untuk memadupadankan warna lukisan, mengidentifikasi jenis burung, menghitung angka pernikahan, dan hadiah untuk anak-anak. Bentuk padu padan inilah, memungkinkan pop up berkolaborasi dengan aplikasi momentCam. Aplikasi momentCam merupakan aplikasi yang terintegrasi dengan ponsel berbasis android. Aplikasi ini mampu mengubah foto menjadi bentuk kartun lucu dengan berbagai pose dan bentuk wajah sesuai yang diinginkan. Cara membuat komik dan kartun pada aplikasi ini sangatlah mudah, kita hanya perlu mengambil foto melalui kamera ponsel kemudian menunggu beberapa saat dan kita tinggal memilih lebih dari seratus kartun dan komik gratis dalam aplikasi tersebut. Pada bagian animasi banyak sekali tersedia "gif" untuk avatar sehingga memudahkan menciptakan gerakan-gerakan lucu, pada bagian komik dapat menciptakan gambar kita dan teman-teman kita, dengan catatan kita harus mengambil terlebih dahulu foto-foto dari sahabat kita. Setelah selesai membuat gambar, kita bisa menyimpan hasilnya di ponsel kita, bahkan dapat dibagian secara langsung melalui facebook, twitter, whatsapp, dan aplikasi lainnya.

Dewie (2015) mengatakan bahwa aplikasi ini memang media edit foto yang unik. Karena memang fasilitas editnya sebenarnya sederhana, tapi menyenangkan sekali hasilnya. Dengan berbagai fitur karakter pilihan, kita akan berimajinasi dalam duniadunia kartun yang fun. dengan warna klasik bertema coklat, berbagai hasil foto pasti akan terlihat lucu dan unik. Berbagai fitur yanga da dalam aplikasi MomentCam adalah fitur bentuk wajah, bentuk tatanan rambut, bentuk alis, bentuk aktivitas, dan bisa edit karakter pria ataupun wanita. Intinya, kita harus menyiapkan sebuah foto yang jelas wajahnya hadap ke depan (diusahakan yang bersih fotonya dengan kualitas bagus) agar hasil editannya pun memuaskan. Fenomena MomentCam semakin menjamur karena banyak orang orang yang tertarik dengan fasilitas ini. Aplikasi momentCam dapat dikatakan sebagai aplikasi alat edit foto yang sangat baik untuk membuat gambargambar yang sempurna sesuai keinginan kita, komposisi yang dihasilkannya pun benarbenar hebat sehingga aplikasi momentCam mampu disandingkan atau dikolaborasi dengan media pop up dalam membantu guru untuk membuat media pembelajaran 3D.

Berdasarkan hasil wawancara dengan kepala sekolah Mts. Bahrul Ulum, guru-guru Mts. Bahrul Ulum belum pernah menggunakan aplikasi momentCam dan media pop up sebagai media pembelajaran 3D di kelas. Oleh karena itu, tim PkM memilih guru-guru di 
sekolah ini sebagai subjek Pengabdian kepada Masyarakat (Pkm). Selain alasan yang dipaparkan di atas, letak Mts. Bahrul Ulum yang berada pada koordinat 7.1990256,111.9612873,15z atau secara kasat mata berada di sebelah tenggara kampus IKIP PGRI Bojonegoro atau sejauh 15,1 km dengan waktu tempuh 27 menit menggunakan kendaraan roda empat membuat tim PkM memilih Mts. Bahrul Ulum sebagai sekolah tempat PkM dilakukan. Adapun foto Mts. Bahrul Ulum tampak pada foto berikut.

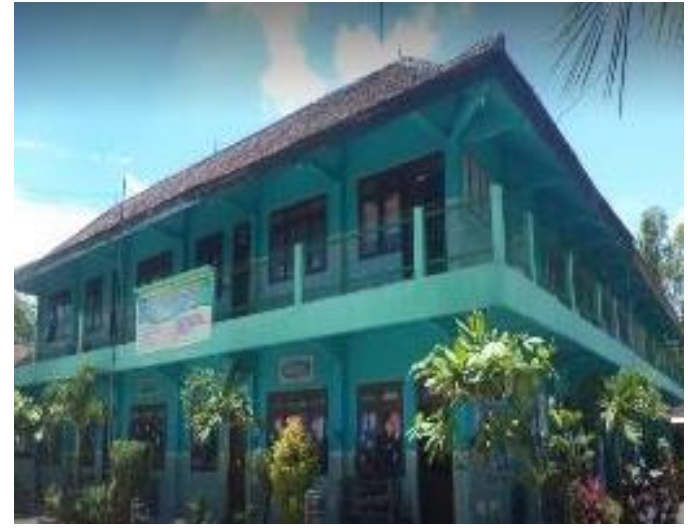

Gambar 1. Foto depan Mts. Bahrul Ulum

Kegiatan pengabdian yang dilakukan layaknya memberikan penyuluhan di dalam kelas, perbedaan di sini, tim akan membuat guru senyaman mungkin dalam menerima materi terkait pembuatan media pop up dan menginstal aplikasi momentcam, selain itu guru juga dituntut untuk mampu membuat satu media pembelajaran yang unik dan inovatif setelah penyuluhan berlangsung.

\section{METODE PELAKSANAAN}

Cara yang dilakukan oleh tim Program Pengabdian kepada Masyarakat (PkM) kepada guru Mts. Bahrul Ulum adalah dengan bentuk kegiatan berikut ini.

1. Melakukan pretes kepada guru Mts. Bahrul Ulum untuk mengetahui pengetahuan awal guru Mts. Bahrul Ulum tentang media pop up dan aplikasi momentcam

2. Penyuluhan dan pembimbingan kepada guru Mts. Bahrul Ulum dalam menginstal dan mengorasikan aplikasi momentcam, serta membuat media popup

3. Mengadakan postes untuk mengetahui tingkat keberhasilan Program Pengabdian kepada Masyarakat (PkM) bagi guru Mts. Bahrul Ulum tentang media pop up dan aplikasi momentcam

4. Tim PKM mengadakan refleksi terhadap kegiatan yang sudah dilakukan pada langkah sebelumnya termasuk memberikan reward kepada guru yang telah membuat media pop up dengan baik.

Setelah mengetahui metode pendekatan yang dilakukan oleh tim Program Pengabdian kepada Masyarakat (PkM) kepada guru Mts. Bahrul Ulum, maka tim pun memiliki rencana kegiatan dan prosedur kegiatan seperti berikut.

\section{Penginstalan Aplikasi MomentCam}

a) Langkah pertama yang harus dilakukan untuk menggunakan aplikasi MomentCam adalah mengunduh aplikasi MomentCam di Google Play Store. Untuk memudahkan 
Anda dalam menemukan aplikasi ini, cukup lakukan pencarian dengan mengetik kata kunci Moman Xiang Ji atau MomentCam. Sebelum mengunduhnya, pastikan kalau kapasitas penyimpanan yang ada di smartphone Anda memiliki kapasitas kosong setidaknya 30 MB. Pasalnya ukuran aplikasi ini cukup besar yaitu 23,29 MB. Dan pastikan juga kalau smartphone Anda memiliki paket data yang cukup untuk proses pengunduhan.

b) Pilih MomentCam dan tekan ikon 'Instal'. Setelah proses download selesai, aplikasi akan secara otomatis terinstal di smartphone Anda.

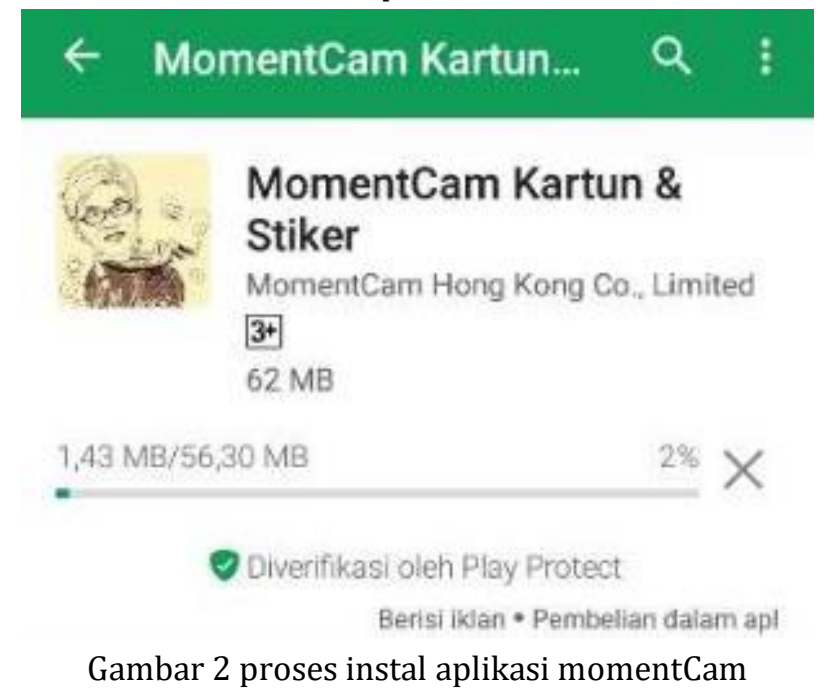

c) Jalankan aplikasi tersebut. Saat membuka aplikasi ini akan muncul tampilan awal dengan pilihan 'Creat Cartoon' atau 'Portfolio'. Untuk memulai membuat karikatur, cukup tekan 'Creat Cartoon' dan akan muncul tampilan seperti gambar di atas. Anda bisa mengambil foto langsung dari kamera ponsel untuk dijadikan foto karikatur atau memilih foto yang sudah ada di galeri ponsel.

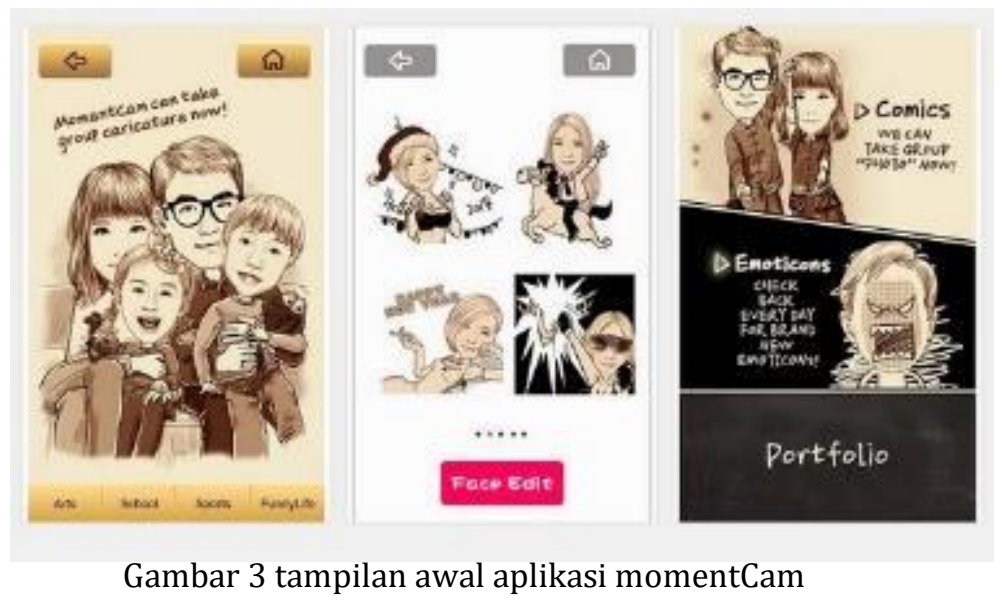

d) Setelah memilih foto yang diinginkan, Anda akan diminta untuk menentukan gender (laki-laki/perempuan). Pilih gender sesuai dengan foto yang kamu pilih dan setelah itu jadilah foto karikatur unik seperti foto di atas. Jangan lupa untuk menyimpan hasil karya Anda dengan memilih ikon bergambar 'Disket' yang terletak di kanan atas. Hasilnya akan tersimpan di galeri ponsel dan 'Portfolio'. Belum cukup sampai di situ, hasil karya Anda juga bisa diedit dengan 
cara membentuk karakter wajah, mengubah gaya rambut, menambahkan aksesoris kacamata, membentuk alis, serta menambahkan kumis dan janggut.

e) Cara mengaplikasikannya, cukup dengan memilih opsi 'Face Edit' yang berisi pilihan Face, Hair style, Glasses, Eyebow, dan Mustach yang ada di bar bawah layar. Anda pun juga bisa merubah desain hasil karikatur dengan memilih opsi 'Design' dan 'Create'.

f) terakhir, hasil karya karikatur Anda dapat di-share ke teman-teman Anda melalui situs jejaring sosial, seperti Facebook dan Twitter, serta pesan instan WeChat.
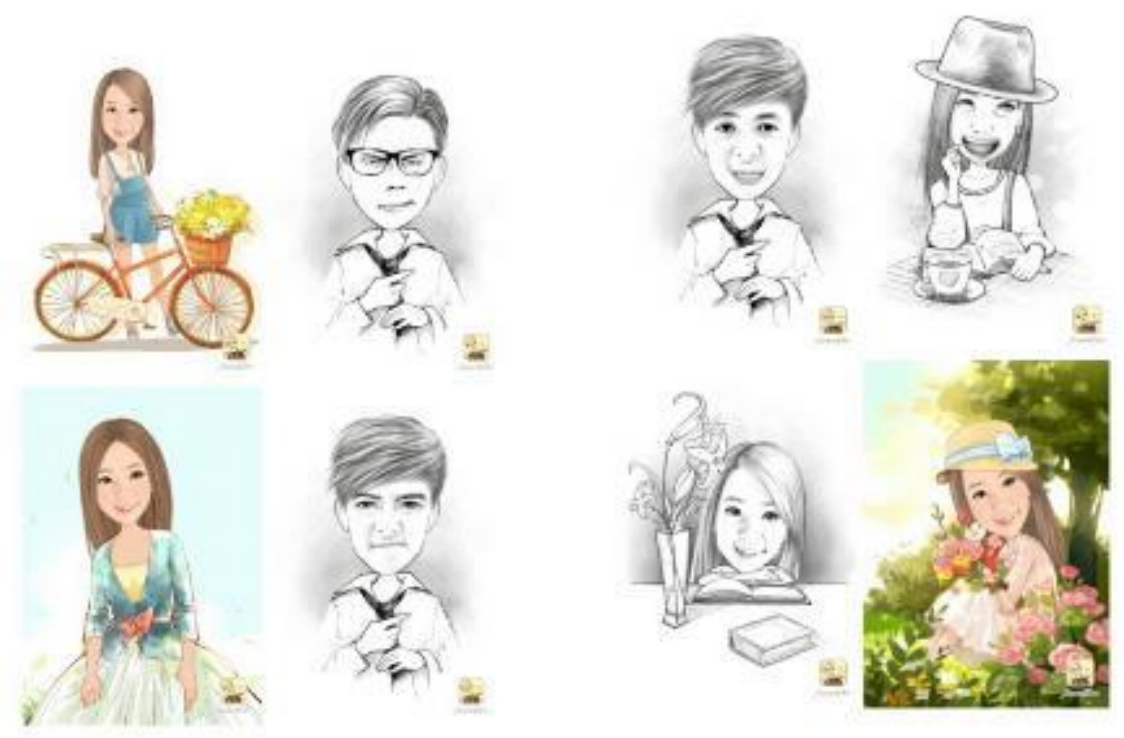

Gambar 4. hasil kartun dengan menggunakan aplikasi momentCam

\section{Pembuatan Media Pop Up}

1. Tulis cerita pendek untuk pop up book ini. Atau, anda dapat mengambil dari cerita yang populer

2. Cetaklah gambar yang telah dibuat dari aplikasi momenCam tersebut

3. Siapkan kertas karton atau jenis lain yang cukup tebal. Kertas ini akan menjadi halaman buku.

4. Potong kertas tersebut sesuai selera. Untuk awalan, potong seukuran setengah halaman A4.

5. Lipat kertas menjadi dua.

6. Gunting sepanjang $1 \mathrm{~cm}$ di punggung kertas (bagian lipatan). Sediakan jarak 0,5 $\mathrm{cm}$ kemudian gunting lagi.

7. Buka lipatan kertas, kemudian tekan bagian yang digunting ke dalam hingga menonjol. Anda akan menempelkan gambar-gambar yang telah dibuat sebelumnya di bagian ini.

8. Posisikan kertas secara melintang (landscape)

9. Tempelkan gambar yang telah dicetak ke bagian dalam kertas yang menonjol. 

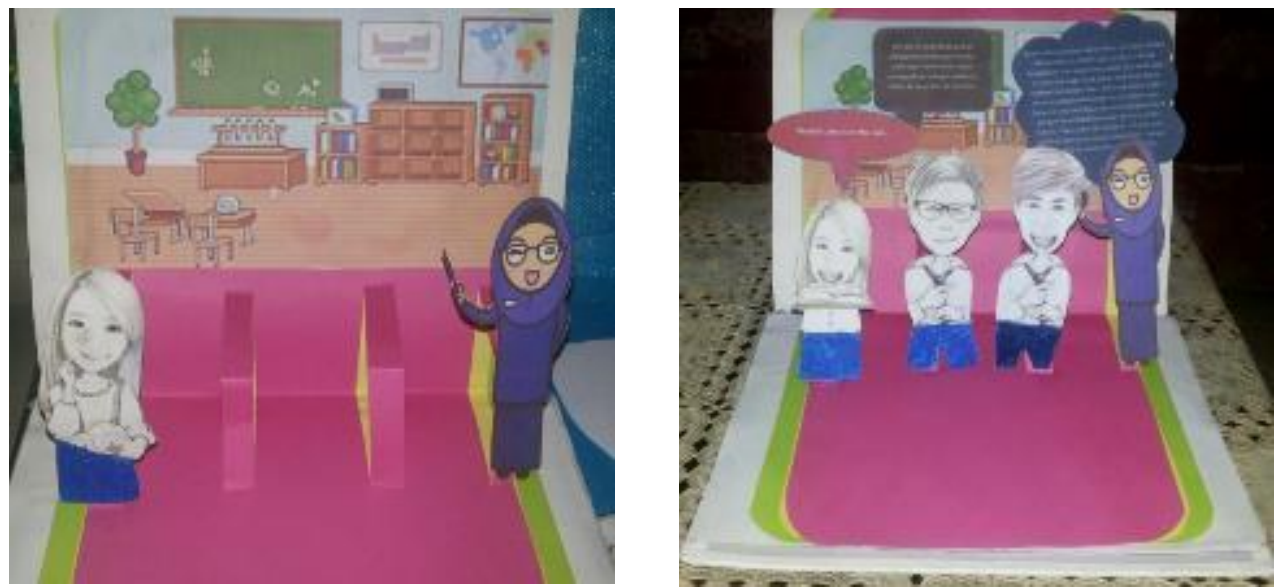

Gambar 5. hasil gambar yang sudah tertempel

10. Jika ingin membuat dua atau lebih gambar tampil menonjol, ulangi langkah 7 dan 8 sesuai kebutuhan. Anda dapat mengatur posisi tonjolan tempat gambar dengan menambah/mengurangi panjang guntingan.

11. Tulis cerita di bagian bawah gambar. Lengkapi pula halaman dengan ilustrasi lain di sekitar gambar.
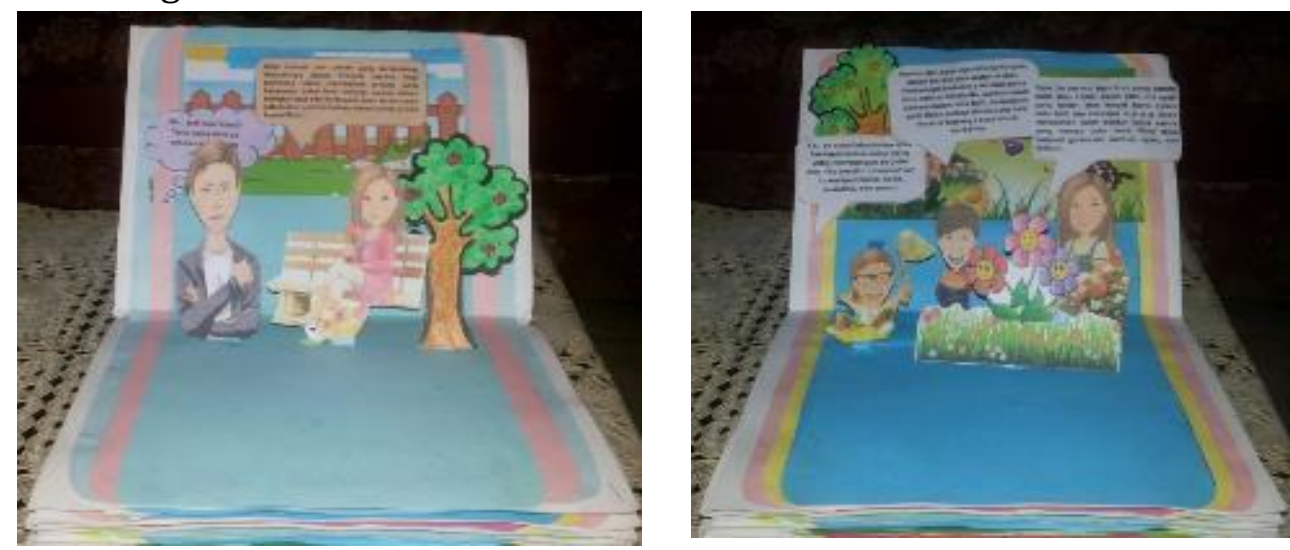

Gambar 6. bentuk pop up yang sudah hampir jadi

12. Satukan halaman-halaman dengan menggunakan lem. Untuk memastikan halaman pop up book dapat dibuka dengan mudah, bagian lipatan buku tidak perlu dilem.
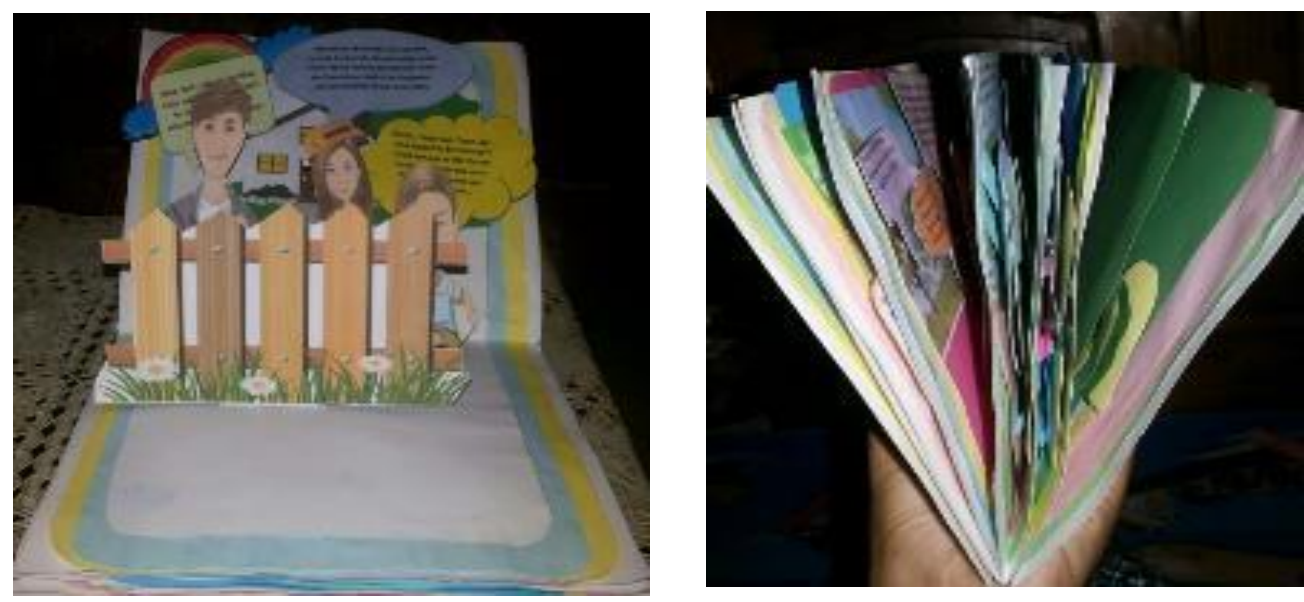

Gambar 7. bentuk halaman pop up 
13. Tulis judul buku di sampul depan dan pop up book pun telah jadi!

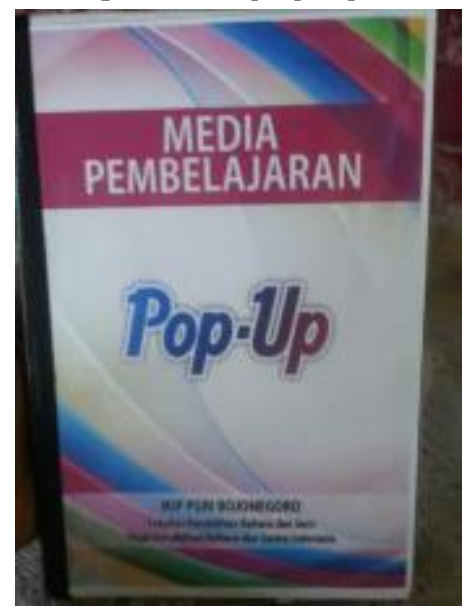

Gambar 8. sampul pop up yang sudah jadi

\section{HASIL DAN PEMBAHASAN}

Untuk mengukur tingkat keberhasilan Program Pengabdian kepada Masyarakat (PkM) kepada guru Mts. Bahrul Ulum maka tim pengabdian membuat skema pengabdian menjadi tiga langkah. langkah tersebut dimulai dari prapengabdian, pengabdian, dan pascapengabdian

\section{Prapengabdian}

Sebelum melakukan langkah prapengabdian, tim melakukan survei lokasi dengan melihat kondisi Mts. Bahrul Ulum, apakah di sekolahan ini, sudah menggunakan jaringan wifi atau belum, kedua kondisi guru-guru di Mts. Bahrul Ulum, apakah sudah pernah diberikan sosialisasi dan loka karya seputar media pop up dan aplikasi momentcamp. Berdasarkan pada dua alasan inilah tim PkM menemukan jawaban bahwa di sekolah tersebut sudah menggunakan jaringan wifi dan guru-guru di sana belum pernah mendapatkan pelatihan tentang pembuatan media pembelajaran 3D. Tim PkM selanjutnya merencanakan melakukan program pengabdian pada hari Senin, 03 September 2018. Setelah kepala sekolah dan tim PkM menyepakati waktu yang telah ditentukan. Tim PkM pun memulai kegiatan pegabdian dengan diawali memberikan soal pretes kepada guru di Mts. Bahrul Ulum. Adapun soal pretes tersebut dapat dilihat pada angket berikut. 


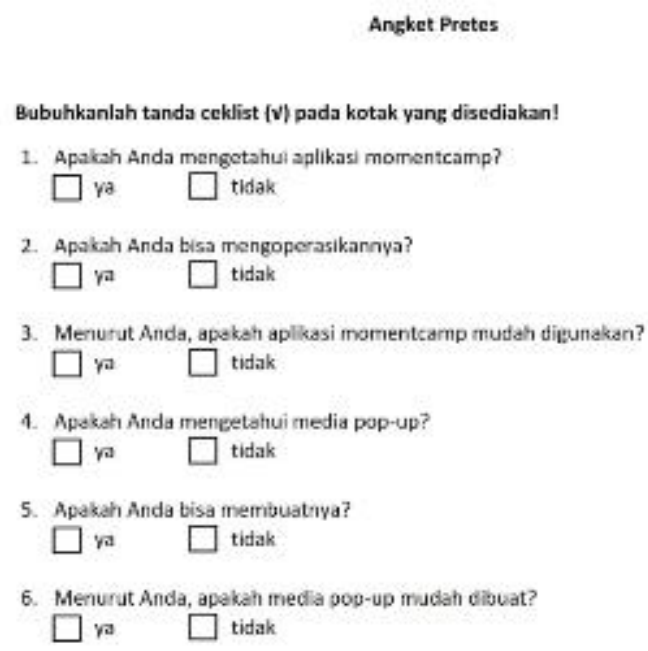

Gambar 9. Angket untuk mengukur pemahaman guru

Hasil pretes menunjukkan bahwa guru di Mts. Bahrul Ulum belum mengetahui media pop up dan aplikasi momentcamp, keenam soal yang diberikan oleh tim Pkm dijawab 'tidak' oleh guru-guru, ada beberapa guru yang menjawab 'ya'. Hal ini dapat dilihat pada diagram berikut.

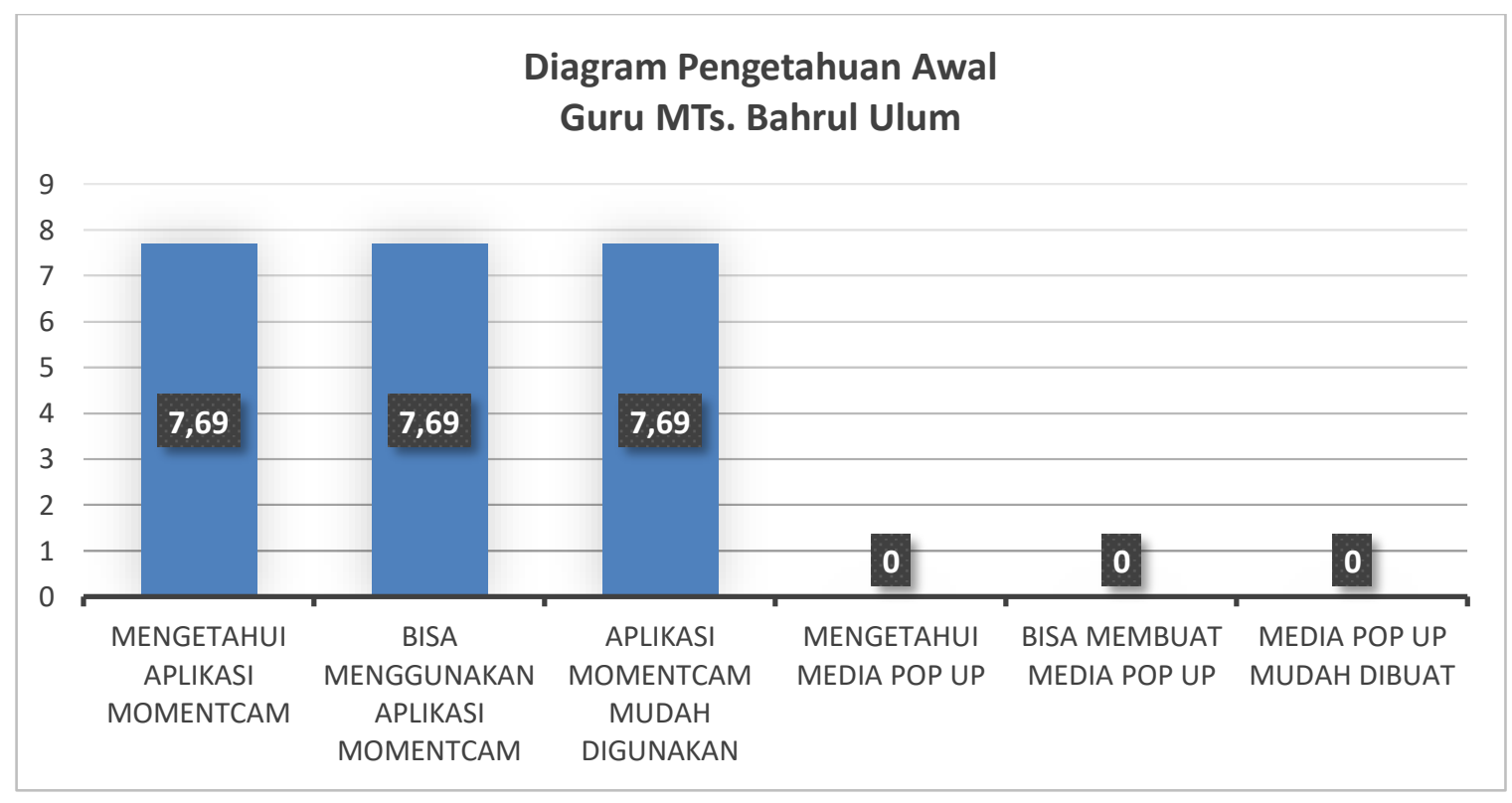

Gambar 10. Hasil Pretes

Hasil angkat tersebut dapat dijelaskan bahwa ada 1 dari 13 guru yang menjawab 'ya' pada tiga butir soal dari enam soal yang diberikan atau sebesar 7,69\%. Setelah melihat hasil angket dan menelaahnya, maka program pengabdian ini layak dilaksanakan. Langkah selanjutnya yang dilakukan peneliti adalah melakukan sosialisasi penginstalan dan pengaplikasian aplikasi momentcam, kemudian lokakarya pembuatan media 3D berbentuk pop up. 


\section{Pengabdian}

Pada langkah pengabdian tim memulai hari pertama dengan memberikan solialisasi tentang cara menginstal dan mengaplikasikan aplikasi momentcam, adapun tutorial kedua cara tersebut dapat dunduh pada link berikut https://www.youtube.com/watch?v=l-bh152aLPA\&t=13s, sedangkan materi PkM dapat diunduh di link berikut https://docs.google.com/presentation/d/19KwP9N396NirRoHy6WWImVp2pwls5uH7ZoNb1Boz s/edit?usp=sharing.

Langkah kedua, tim PkM mengajak guru-guru untuk membuat media pop up dengan memanfaatkan karakter yang sudah dibuat oleh guru-guru pada aplikasi momentcam, pembuatan media ini mengikuti langkah-langkah yang ada pada bab sebelumnya. Pada langkah ini, guru senantiasa mengikuti instruksi yang diberikan oleh tim PkM, tidak jarang dari mereka menanyakan perihal cara mengelem dengan sempurna, cara membuat guntingan dalam guntingan kertas yang sudah jadi. Sehingga pada program ini tidak ada satu pun guru yang tidak bisa membuat media pop up. Adapun salah satu media pop up yang sudah dapat dibuat oleh guru Mts. Bahrul Ulum dapat dilihat pada gambar berikut.
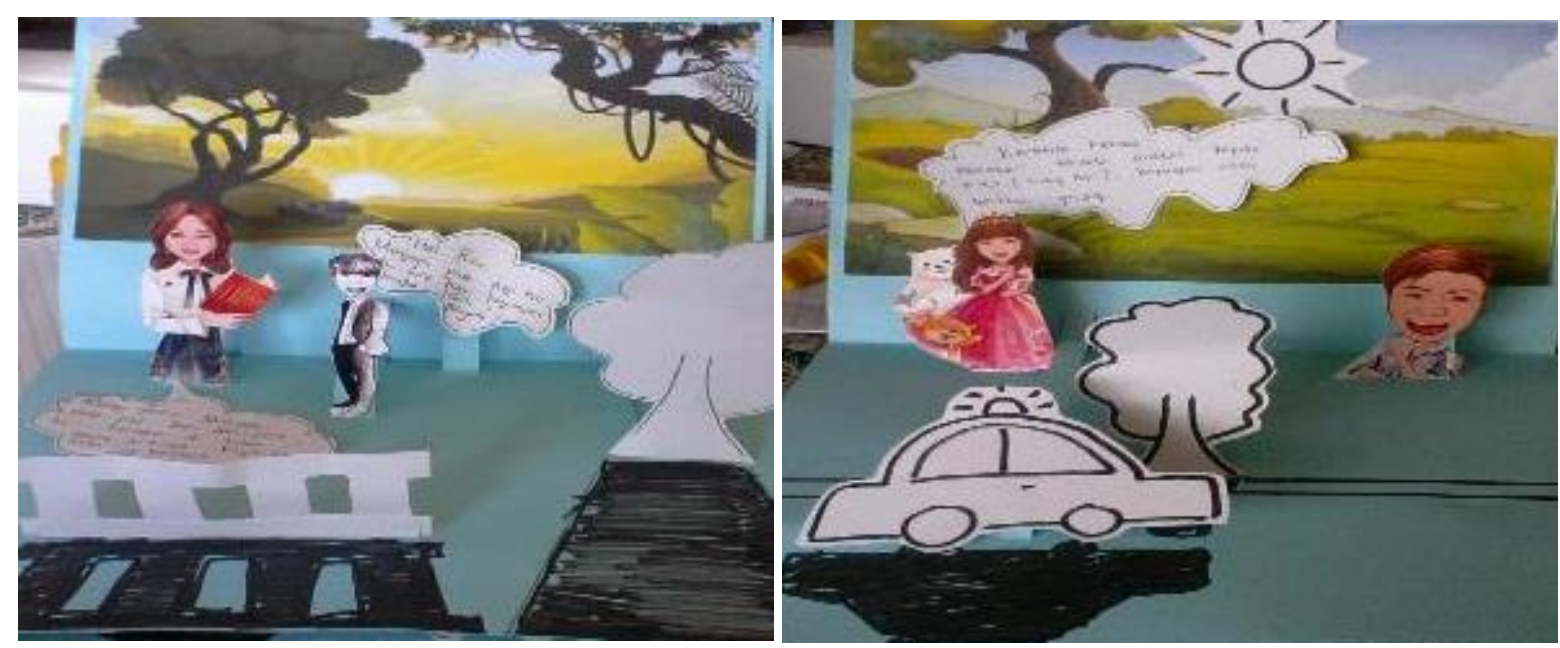

Gambar 11. Hasil media pop up guru Mts. Bahrul Ulum

\section{Pascapengabdian}

Pada langkah pascapengabdian, tim Pengabdian memberikan soal postes untuk mengetahui tingkat keberhasilan pengabdian yang dilakukan oleh tim terkait pengoperasian aplikasi momentcam dan membuatan media pop up. Soal postes yang diberikan sama dengan soal pada pretes, namun tim PkM menambahkan pertanyaan terbuka pada soal postes dengan berasumsi bahwa program pengabdian berhasil atau tidak. Untuk mengetahui tingkat keberhasilan program pengabdian, maka dapat dilihat jumlah guru yang menjawab 'ya' dari hasil postes yang telah dikerjakan pada diagam berikut. 


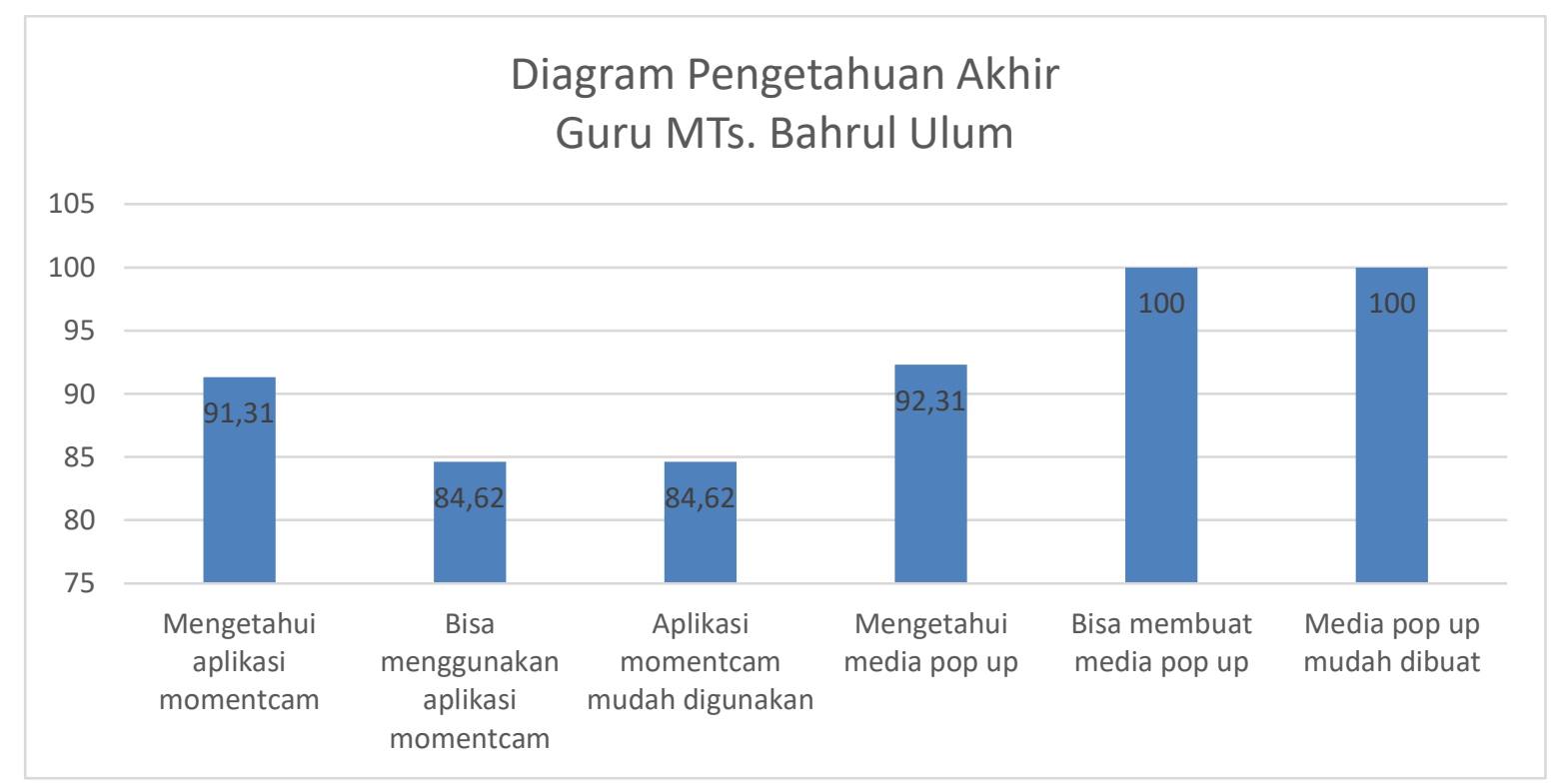

Gambar 12. Hasil Postes

Hasil postes menunjukkan bahwa guru-guru di Mts. Bahrul Ulum mengetahui aplikasi momentcam sebanyak 12 orang atau 91,31\%, dapat menggunakan aplikasi momentcam sebanyak 11 orang atau 84,62\%, aplikasi momentcam mudah digunakan menurut 11 orang atau 84,62\%, mengetahu media pop up sebanyak 12 orang atau 92,31\%, dan semua guru Mts. Bahrul Ulum mampu membuat media pop up serta mengatakan bahwa media pop up itu mudah dibuat. Hasil pretes pada langkah prapengabdian dan postes pada langkah pascapengabdian dapat digambarkan pada tabel berikut.

Tabel 1. Rekap hasil pretes dan postes

\begin{tabular}{|l|l|l|}
\hline \multicolumn{1}{|c|}{ Indikator } & $\begin{array}{c}\text { Nilai } \\
\text { Pretes } \\
\text { (\%) }\end{array}$ & $\begin{array}{c}\text { Nilai } \\
\text { Postes } \\
\text { (\%) }\end{array}$ \\
\hline Mengetahui aplikasi momentcam & 7,69 & 91,31 \\
\hline Bisa menggunakan aplikasi momentcam & 7,69 & 84,62 \\
\hline Aplikasi momentcam mudah digunakan & 7,69 & 84,62 \\
\hline Mengetahui media pop up & 0,00 & 92,31 \\
\hline Bisa membuat medua pop up & 0,00 & 100 \\
\hline Media pop up mudah dibuat & 0,00 & 100 \\
\hline
\end{tabular}

Berdasarkan pada tabel hasil rekap di atas, dapat dikatakan bahwa Program Pengabdian kepada Masyarakat (PkM) dengan memberikan pelatihan pembuatan media pembelajaran3D melalui media aplikasi momentcam dan media pop up di MTs. Bahrul Ulum berhasil. Keberhasilan program ini dapat dilihat dari manfaat yang dirasakan oleh guru-guru di sana, yaitu guru dapat menciptakan media sendiri dan mampu mengekpresikan keterampilannya dalam menggambar, menggunting dan menempel di media pop up. Hal ini dapat dilihat pada hasil angket berikut. 


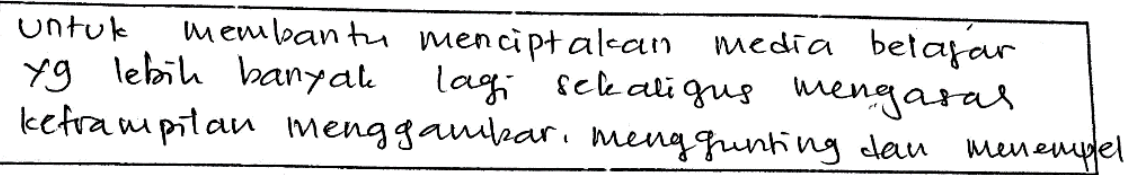

Gambar 13. Hasil Angket 1

Keberhasilan program pengabdian ini juga dapat dilihat dari komitmen Guru MTs. Bahrul Ulum untuk menerapkan hasil program pengabdikan ini kepada peserta didik agar peserta didik mudah memahami materi ajar melalui media pop up. Hal ini dapat dilihat pada angket berikut.

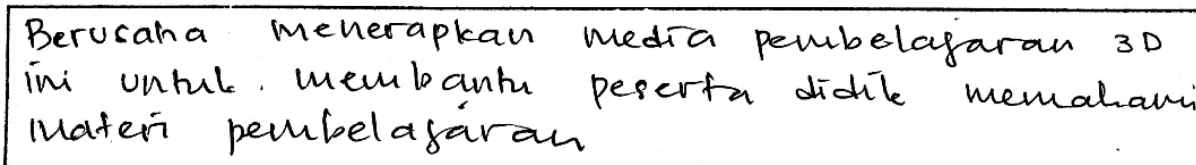

Gambar 14. Hasil Angket 2

\section{SIMPULAN}

Simpulan Program Pengabdian kepada Masyarakat (PkM) ini adalah guru-guru di Mts. Bahrul Ulum bisa menginstal dan mengoperasikan aplikasi momentcam melalui telepon selulur (HP) mereka, hasil mengoprasikan aplikasi momentcam dapat dilihat dari karakter-karakter yang dapat dibuat dan dicetak oleh guru-guru MTs. Bahrul Ulum. Setelah guru dapat mengoprasikan aplikasi momentcam, selanjutnya guru membuat media pop up mengikuti langkah yang sudah diinstruksikan, pop up yang sudah jadi kemudian dikolaborasikan dengan karakter-karakter yang telah dicetak. Bentuk kolaborasi ini menjadikan guru-guru di Mts. Bahrul Ulum mampu membuat media pembelajaran 3D.

\section{DAFTAR RUJUKAN}

Dewie, R. (2015) https://www.kompasiana.com/rianadewie/552c31ae6ea83 43e128b4575/fenomena-momentcam-di-android-apa-ini

http://sahabatmembaca.org/2015/12/12/membuat-pop-up-book/

https://docs.google.com/presentation/d/19KwP9N396NirRoHy6WWImVp2pwls5uH7ZoNb1Boz_s/edit?usp=sharing

https://www.liputan6.com/tekno/read/745237/cara-membuat-karikatur-denganaplikasi-momentcam\#

https://www.youtube.com/watch?v=l-bh152aLPA\&t=13s

Puleo, B. (2011). NEXT STOP:POP-UPS. Pennsylvania: Marywood University.

Van Dyk, S. and Hewitt, C. (2011). Paper Engineering: Fold, Pull, Pop \& Turn. National Museum of American History Washington, DC: The Smithsonian Libraries Exhibition Gallery. 
146 J-Abdipamas, Vol. 2, No. 2, Oktober 2018 